\title{
PEMANFAATAN TANAMAN OBAT OLEH MASYARAKAT DI SEKITAR HUTAN DESA SEMANDANG KIRI KECAMATAN SIMPANG HULU KABUPATEN KETAPANG
}

\author{
(Utilization of Medicinal Plants by The Community Around In Semandang Kiri Village \\ subdistrict Simpang Hulu District Ketapang)
}

\author{
Yulius Rio Julio, M. Idham, Oramahi \\ Fakultas Kehutanan Universitas Tanjungpura Jl. Daya Nasional, Pontianak 78124 \\ Email : yuliusriojulio95@gmail.com
}

\begin{abstract}
Medicinal plants are one of the important components in medicine, which are traditional herbal remedies and have been used since hundreds of years ago, to solve various health problems it faces. Therefore traditional medicine needs to be nurtured, cared for and preserved, because it is a wealth of Indonesian culture. This study aims to obtain data on the number and type of medicinal plants as well as the use of medicinal plants, among others, how to mix medicinal ingredients, how to treat them and their efficacy by the people in Semandang Kiri Village, Simpang Hulu Subdistrict, Ketapang Regency. The benefits of this study are expected to be able to take action to preserve the existence of traditional medicinal plants so that they can be utilized optimally and sustainably by the people in the Semandang left village in the upstream intersection of Ketapang Regency, and can provide useful information on medicinal plants. This research is descriptive in nature using the snowball sampling technique or carried out sequentially by asking for information on the person interviewed or contacted beforehand. Based on the results of research on the types of medicinal plants used by communities around the Semandang Kiri village, the upstream intersection of Ketapang District, 56 species of medicinal plants were found in 38 families and the use of medicinal plants most utilized from 56 species.
\end{abstract}

Keywords: Medicinal plants, utilization, traditional medicine

\section{PENDAHULUAN}

Tanaman obat merupakan salah satu komponen penting dalam pengobatan, yang berupa ramuan jamu tradisonal dan telah digunakan sejak ratusan tahun lalu, untuk memcahkan berbagai masalah kesehatan yang dihadapinya. Oleh karena itu pengobatan tradisonal perlu dipelihara, diperhatikan dan dilestarikan, karena merupakan kekayaan budaya bangsa Indonesia. Pengembangan obat alami ini memang patut mendapatkan perhatian yang lebih besar bukan saja disebabkan potensi pengembangannya yang terbuka, tetapi juga permintaan pasar akan bahan baku obat-obat tradisional ini terus meningkat baik untuk kebutuhan domestik maupun internasional. Hal ini tentunya juga akan berdampak positif bagi penyerapan tenaga kerja baik dalam usaha tani maupun dalam usaha pengolahannya, sehingga pendapatan petani meningkat. Pengetahuan tradisional yang dimiliki setiap suku/etnis dalam memanfaatkan tanaman merupakan unsur budaya yang muncul dari pengalaman individu yang disebabkan adanya interaksi dengan lingkungannya dan diwariskan secara 
turun temurun yang bertujuan untuk mempertahankan hidup, karena baik disadari maupun tidak dalam mempertahankan kelangsungan hidupnya, manusia akan selalu bergantung terhadap lingkungannya dan begitu pula sebaiknya. Beberapa hasil penelitian terdahulu ternyata masingmasing daerah di Kalimantan Barat banyak ditemukan jenis-jenis tanaman obat. Penelitian yang dilakukan Armiwoltywa (2011) di Dusun Marinso Kabupaten Landak terdapat 30 jenis tanaman obat. Maryadi (2012) di Desa Seriang Kecamatan Badau Kabupaten Kapuas Hulu terdapat 41 jenis tanaman obat. Leonardo dkk (2012) mengetahui bahwa di Desa Sekabuk Kabupaten Pontianak terdapat 51 jenis tanaman obat.

Masyarakat Desa Semandang Kiri Kecamatan Simpang Hulu Kabupaten Ketapang merupakan masyarakat yang secara tradisional mengobati berbagai macam penyakit dengan menggunakan tanaman yang ada di dalam hutan atau pun di sekitar tempat tinggal yang dipercaya sebagai obat. Namun data pengobatan tersebut belum terdokumentasi, sehingga informasi pengobatan tersebut hanya dari mulut ke mulut. Oleh karena itu perlu dilakukan penelitian untuk mengungkapkan pengetahuan tentang bagaimana pengobatan tradisional yang dilakukan dengan memanfaatkan tanaman obat yang ada. Penelitian ini bertujuan untuk memperoleh data jumlah dan jenis tanaman obat serta pemanfaatan tanaman obat antara lain cara meramu bahan obat, cara pengobatan dan khasiatnya oleh masyarakat di Desa Semandang Kiri Kecamatan Simpang Hulu Kabupaten Ketapang. Manfaat dari penelitian ini diharapkan dapat dilakukan tindakan pelestarian terhadap keberadaan tanaman obat tradisional ini agar dapat dimanfaatkan secara optimal dan berkelanjutan oleh masyarakat di desa semandang kiri kecamatan simpang hulu kabupaten ketapang, serta dapat memberikan data-data informasi yang berguna mengenai tanaman obat.

\section{METODE PENELITIAN}

Penelitian ini dilakukan di Desa Semandang Kiri Kecamatan Simpang Hulu Kabupaten Ketapang. Jenis data yang diambil dalam penelitian ini adalah data primer dan data sekunder. Data primer adalah data yang dikumpulkan langsung oleh peneliti dari hasil observasi di lapangan dengan cara wawancara dengan masyarakat di Desa Semandang Kiri Kecamatan Simpang Hulu Kabupaten Ketapang, data sekunder merupakan data pelengkap yang diperoleh dari referensi yang meliputi keadaan umum lokasi, keadaan sosial budaya, aksibilitas dan lain-lain.

Penelitian ini bersifat deskriptif yang menggunakan teknik snowball sampling atau dilakukan secara berantai dengan meminta informasi pada orang yang telah diwawancarai atau dihubungi sebelumnya (Nurhaida dkk 2015). Berdasarkan wawancara dilakukan pencatatan mengenai keterangan jenisjenis tanaman yang dimanfaatkan sebagai bahan pengobatan masyarakat 
setempat (responden). Proses penentuan responden dalam penelitian ini peneliti akan meminta rekomendasi calon responden dari kepala desa, kepala adat, kepala dusun,dukun, tabib, pengguna, orang tua, dan masyarakat pengguna. Peneliti tidak akan membatasi jumlah responden maupun objek penelitian. Pengambilan data akan dihentikan apabila peneliti telah mendapat data yang selalu sama.

\section{HASIL DAN PEMBAHASAN}

1. Tanaman Obat Yang Di Manfaatkan Di Masyarakat

\section{Tabel 1. Spesies tanaman obat yang dimanfaatkan (Medicinal plant species used)}

\begin{tabular}{|c|c|c|c|c|}
\hline No & Nama Lokal & Nama Ilmiah & Family & Habitus \\
\hline 1 & Asam Jawa & Tamarindus indica $\mathrm{L}$ & Caesalpiniaceae & Pohon \\
\hline 2 & Belimikng & Averrhoa carambola $\mathrm{L}$ & Oxalidaceae & Pohon \\
\hline 3 & Borak & Musa paradisiacal & Musaceae & Pohon \\
\hline 4 & Buloh Kuning & Bambusa vulgaris & Poaceae & Pohon \\
\hline 5 & Bunga Kelapak & Jasminum sp & Oleaceae & Semak \\
\hline 6 & Ceronga & Impatiens balsamina $\mathrm{L}$ & Balsaminaceae & Herba \\
\hline 7 & Cocor Bebek & Kalanchoe pinnata (Lam.) & Crassulaceae & Herba \\
\hline 8 & Cokor & Kaempferi sp & Zingiberaceae & Herba \\
\hline 9 & Cuncung & Celosia argentea & Amaranthaceae & Semak \\
\hline 10 & Daun Ungu & Graptophyllum hortense Nees & Acanthaceae & Herba \\
\hline 11 & Diatn & Durio zibethinus Murr & Bombacaceae & Pohon \\
\hline 12 & Gerinang & Averrhoa bilimbi $\mathrm{L}$ & Oxalidaceae & Pohon \\
\hline 13 & Jamu Tukal & Psidium guajava & Myrtaceae & Pohon \\
\hline 14 & Jerongau & Acarus calamus $\mathrm{L}$ & Araceae & Herba \\
\hline 15 & Joring & Pithecollobium lobatum Benth & Fabaceae & Pohon \\
\hline 16 & Karek & Hevea brasiliensis & Euphorbiaceae & Pohon \\
\hline 17 & Kase & Curcuma xanthorrhiza Roxb & Zingiberaceae & Herba \\
\hline 18 & Katepeng & Cassia alata $\mathrm{L}$ & Fabaceae & Semak \\
\hline 19 & Kemangi & Ocinum cannum & Ocinaceae & Semak \\
\hline 20 & Ketapang & Terminalia cattapa & Combretaceae & Pohon \\
\hline 21 & Komakng Kamak & Hibiscus rosasinensis $\mathrm{L}$. & Malvaceae & Semak \\
\hline 22 & Komakng Pangel & Clerodendrum paniculatum & Verbenaceae & Semak \\
\hline 23 & Kumis Kucing & Orthosiphon aristatus & Lamiaceae & Semak \\
\hline 24 & Kunyetn & Curcuma domestica Val & Zingiberaceae & Herba \\
\hline 25 & Lalakng & Imperata cylindrica & Graminaceae & Herba \\
\hline 26 & Lam Belana & Artemisia vulgaris $\mathrm{L}$ & Asteraceae & Herba \\
\hline
\end{tabular}

Desa Semandang Kiri Kecamatan Simpang Hulu Kabupaten Ketapang, ditemukan 56 spesies dari 38 family yang dimanfaatkan sebagai obat, dimana pengolahannya masih sangat sederhana yang telah dilakukan secara turun temurun dari zaman nenek moyang dan satu jenis tanaman obat dapat digunakan untuk mengobati penyakit yang sama, hal ini menunjukkan bahwa pengobatan tradisional masih digemari masyarakat karena sudah terbukti khasiatnya. 


\begin{tabular}{|c|c|c|c|c|}
\hline No & Nama Lokal & Nama Ilmiah & Family & Habitus \\
\hline 27 & Lengkuas & Alpinia galanga & Zingiberaceae & Herba \\
\hline 28 & Mamokng & Blumea balsamiferaa $\mathrm{L}$ & Compositae & Semak \\
\hline 29 & Mangis & Garcinia mangostana $\mathrm{L}$ & Cluciaceae & Pohon \\
\hline 30 & Mahkota Dewa & Phaleria macrocarpa & Thymelaeceae & Pohon \\
\hline 31 & Mengkudu & Morinda citrifolia $\mathrm{L}$ & Rubiaceae & Pohon \\
\hline 32 & Renas Korang & Rhoeo spatacea Swart & Commelinaceae & Semak \\
\hline 33 & Nangka Belana & Annona muricata $\mathrm{L}$ & Annoaceae & Pohon \\
\hline 34 & Nyor & Cocos nueifera & Arecaceae & Pohon \\
\hline 35 & Nyori & Coix agrestis Lour & Poaceae & Herba \\
\hline 36 & Pakawe & Durio kutejensis & Bombacaceae & Pohon \\
\hline 37 & Pasak Bumi & Eurycoma longifolia & Rubiaceae & Pohon \\
\hline 38 & Patah Kemudi & Elephantopus scaber L & Asteraceae & Herba \\
\hline 39 & Pepaya & Carica papaya $\mathrm{L}$ & Caricaceae & Semak \\
\hline 40 & Pinang & Areca catechu & Palmae & Pohon \\
\hline 41 & Pokuh Borok & Blechnum orientale $\mathrm{L}$ & Polypodiaceae & Herba \\
\hline 42 & Pokuh Kabokng & Diplazium esculentum & Polypodiaceae & Herba \\
\hline 43 & Pokuh Naitn & Polystichum setiferum & Athyriaceae & Herba \\
\hline 44 & Roih & zingiber officinale & Zingiberaceae & Herba \\
\hline 45 & Rosat & Lansium domesticum & Meliaceae & Pohon \\
\hline 46 & Sabang Merah & Cordyline fruticosa $\mathrm{L}$ & Liliaceae & Semak \\
\hline 47 & Sago & Metroxylon sagu Rottb & Arecaceae & Pohon \\
\hline 48 & Sahang & Piper albi Linn & Piperaceae & Liana \\
\hline 49 & Sangset & Physalis peruviana $\mathrm{L}$ & Solanaceae & Semak \\
\hline 50 & Sensabi Borok & Isotoma longiflora Presl & Campanulaceae & Semak \\
\hline 51 & Sireh & Piper betle Linn & Piperaceae & Liana \\
\hline 52 & Sorai & Cymbopogon nardus Linn & Poaceae & Herba \\
\hline 53 & Sugi Pink & Gomphrena globosa & Amaranthaceae & Semak \\
\hline 54 & Tiong Mansam & Solanum ferox Linn & Solanaceae & Semak \\
\hline 55 & Tiong Pipit & Solanum torvum $S w$ & Solanaceae & Semak \\
\hline 56 & Tobuh Mirah & Saccharum officinarum L & Poaceae & Herba \\
\hline
\end{tabular}

Masyarakat Desa Semandang Kiri temurun seperti bagian yang digunakan, memanfaatkan tanaman obat cara pengolahan, cara penggunaan dan berdasarkan pengetahuan yang lain sebagainya, untuk lebih jelasnya diwariskan orang tuanya secara turun dapat dilihat pada Tabel 2. 
Tabel 2. Jenis tanaman obat dan pemanfaatannya (Types of medicinal plants and their uses)

\begin{tabular}{|c|c|c|c|c|c|}
\hline No & Nama Lokal & $\begin{array}{l}\text { Bagian Yang } \\
\text { Digunakan }\end{array}$ & $\begin{array}{l}\text { Cara } \\
\text { Pengolahan }\end{array}$ & $\begin{array}{l}\text { Cara } \\
\text { Penggunaan }\end{array}$ & Manfaat \\
\hline 1 & Asam Jawa & Buah & Direbus & Diminum & $\begin{array}{l}\text { Sakit panas dan } \\
\text { demam }\end{array}$ \\
\hline 2 & Belimikng & Buah dan daun & $\begin{array}{l}\text { Langsung, } \\
\text { direbus }\end{array}$ & $\begin{array}{l}\text { Dimakan, } \\
\text { diminum }\end{array}$ & $\begin{array}{l}\text { Hipertensi, } \\
\text { malaria dan maag }\end{array}$ \\
\hline 3 & Borak & Jantung buah & $\begin{array}{l}\text { Direbus, } \\
\text { dimasak }\end{array}$ & Dimakan & Melancarkan ASI \\
\hline 4 & Buloh Kuning & Akar & Direbus & Dimakan & Sakit Kuning \\
\hline 5 & Bunga Kelapak & Getah & Langsung & Dioles & Luka \\
\hline 6 & Ceronga & Daun & Ditumbuk & Dioles & Luka \\
\hline 7 & Cocor Bebek & Daun & Diremas & Ditempel & Sakit lepuh \\
\hline 8 & Cokor & Rimpang & $\begin{array}{l}\text { Diparut, } \\
\text { direbus } \\
\text { tambah } \\
\text { garam }\end{array}$ & Diminum & Sakit perut \\
\hline 9 & Cuncung & Biji & Direbus & Diminum & $\begin{array}{l}\text { Tekanan darah } \\
\text { tinggi }\end{array}$ \\
\hline 10 & Daun Ungu & Bunga & Direbus & Diminum & Melancarkan Haid \\
\hline 11 & Diatn & Kulit buah & Ditumbuk & Ditempel & Sakit perut \\
\hline 12 & Gerinang & Buah, daun & $\begin{array}{l}\text { Langsung, } \\
\text { direbus }\end{array}$ & $\begin{array}{l}\text { Dimakan, } \\
\text { diminum }\end{array}$ & $\begin{array}{l}\text { Darah tinggi, } \\
\text { gatal-gatal }\end{array}$ \\
\hline 13 & Jamu Tukal & Daun & Direbus & Diminum & Sakit perut \\
\hline 14 & Jerongau & Rimpang & Direbus & Diminum & Sakit perut \\
\hline 15 & Joring & Buah & Langsung & Dimakan & Sakit jantung \\
\hline 16 & Karek & Getah & Langsung & Dioles & Luka \\
\hline 17 & Kase & Rimpang & Direbus & Diminum & Keputihan \\
\hline 18 & Katepeng & Daun & Ditumbuk & Dioles & Panu, kurap \\
\hline 19 & Kemangi & Biji & Direbus & Diminum & Panas dalam \\
\hline 20 & Ketapang & Biji, daun & $\begin{array}{l}\text { Ditumbuk, } \\
\text { tambah gula } \\
\text { batu, air }\end{array}$ & $\begin{array}{l}\text { Dimakan, } \\
\text { ditempel }\end{array}$ & $\begin{array}{l}\text { Melancarkan ASI, } \\
\text { rematik }\end{array}$ \\
\hline 21 & Komakng Kamak & Daun & Ditumbuk & Ditempel & Batuk darah \\
\hline 22 & Komakng Pangel & Daun & $\begin{array}{l}\text { Dihaluskan, } \\
\text { dicampur } \\
\text { madu }\end{array}$ & Ditempel & Koreng, bisul \\
\hline 23 & Kumis Kucing & Seluruh bagian & Direbus & Diminum & Kencing manis \\
\hline 24 & Kunyetn & Rimpang & $\begin{array}{l}\text { Diparut, } \\
\text { tambah air } \\
\text { asam, gula, } \\
\text { disaring }\end{array}$ & Diminum & $\begin{array}{l}\text { Demam, } \\
\text { keputihan }\end{array}$ \\
\hline 25 & Lalakng & Akar & Direbus & Diminum & Rematik \\
\hline
\end{tabular}




\begin{tabular}{|c|c|c|c|c|c|}
\hline No & Nama Lokal & $\begin{array}{l}\text { Bagian Yang } \\
\text { Digunakan }\end{array}$ & $\begin{array}{l}\text { Cara } \\
\text { Pengolahan }\end{array}$ & $\begin{array}{l}\text { Cara } \\
\text { Penggunaan }\end{array}$ & Manfaat \\
\hline 26 & Lam Belana & Daun & $\begin{array}{l}\text { Ditumbuk, } \\
\text { diperas } \\
\text { tambah air }\end{array}$ & Diminum & $\begin{array}{l}\text { Sakit } \\
\text { tenggorokkan }\end{array}$ \\
\hline 27 & Lengkuas & Rimpang & Direbus & Diminum & Demam \\
\hline 28 & Mamokng & Daun & $\begin{array}{l}\text { Direbus, } \\
\text { ditumbuk }\end{array}$ & $\begin{array}{l}\text { Diminum, } \\
\text { ditempel }\end{array}$ & $\begin{array}{l}\text { Nyeri haid, luka } \\
\text { memar }\end{array}$ \\
\hline 29 & Mangis & Kulit Buah & Direndam & Diminum & Diare \\
\hline 30 & Mahkota Dewa & Buah & Direbus & Diminum & Kanker Payudara \\
\hline 31 & Mengkudu & Buah & Direbus & Diminum & Darah tinggi \\
\hline 32 & Renas Korang & Daun & Direbus & Diminum & Mimisan \\
\hline 33 & Nangka Belana & Daun & $\begin{array}{l}\text { Direbus, } \\
\text { ditumbuk }\end{array}$ & $\begin{array}{l}\text { Diminum, } \\
\text { Ditempel }\end{array}$ & $\begin{array}{l}\text { Darah tinggi, } \\
\text { penurun panas, } \\
\text { luka }\end{array}$ \\
\hline 34 & Nyor & Akar, buah & $\begin{array}{l}\text { Direbus, } \\
\text { langsung }\end{array}$ & Diminum & Demam, cacar \\
\hline 35 & Nyori & Akar & Direbus & Diminum & Usus buntu \\
\hline 36 & Pakawe & Daging buah & Dikupas & Dimakan & Sakit kepala \\
\hline 37 & Pasak Bumi & Batang & Direbus & Diminum & $\begin{array}{l}\text { Menurunkan } \\
\text { panas }\end{array}$ \\
\hline 38 & Patah Kemudi & Daun & Direbus & Diminum & Sakit perut \\
\hline 39 & Pepaya & Daun & Direbus & Dimakan & Malaria \\
\hline 40 & Pinang & Akar, biji & $\begin{array}{l}\text { Direbus, } \\
\text { tambah akar } \\
\text { kelapa }\end{array}$ & Diminum & $\begin{array}{l}\text { Memar, } \\
\text { mengecilkan } \\
\text { rahim }\end{array}$ \\
\hline 41 & Pokuh Borok & Daun, batang & Ditumbuk & Ditempel & Bisul, bekas luka \\
\hline 42 & Pokuh Kabokng & Getah, daun & Ditumbuk & Ditempel & $\begin{array}{l}\text { Menghilangkan } \\
\text { bekas luka }\end{array}$ \\
\hline 43 & Pokuh Naitn & Daun & Dimasak & Dimakan & Kurang darah \\
\hline 44 & Roih & Rimpang & $\begin{array}{l}\text { Direbus, } \\
\text { langsung }\end{array}$ & $\begin{array}{l}\text { Diminum, } \\
\text { dimakan }\end{array}$ & $\begin{array}{l}\text { peluruh keringat, } \\
\text { penambah nafsu } \\
\text { makan dan } \\
\text { melancarkan ASI }\end{array}$ \\
\hline 45 & Rosat & Kulit pohon & Direbus & Diminum & Malaria \\
\hline 46 & Sabang Merah & Daun & Dipanaskan & Ditempel & Luka sengatan \\
\hline 47 & Sago & Akar & Direbus & Diminum & Diare \\
\hline 48 & Sahang & Biji & $\begin{array}{l}\text { Ditumbuk } \\
\text { campur air }\end{array}$ & Ditempel & $\begin{array}{l}\text { Masuk angin, } \\
\text { sakit kepala }\end{array}$ \\
\hline 49 & Sangset & Daun & Direbus & Diminum & Masuk angin \\
\hline 50 & Sensabi Borok & Daun & Ditumbuk & Ditempel & Sakit gigi \\
\hline 51 & Sireh & Daun & Langsung & Ditempel & Mimisan \\
\hline 52 & Sorai & Batang & Ditumbuk & Ditempel & Keseleo \\
\hline 53 & Sugi Pink & Daun & Direbus & Diminum & Melancarkan \\
\hline
\end{tabular}




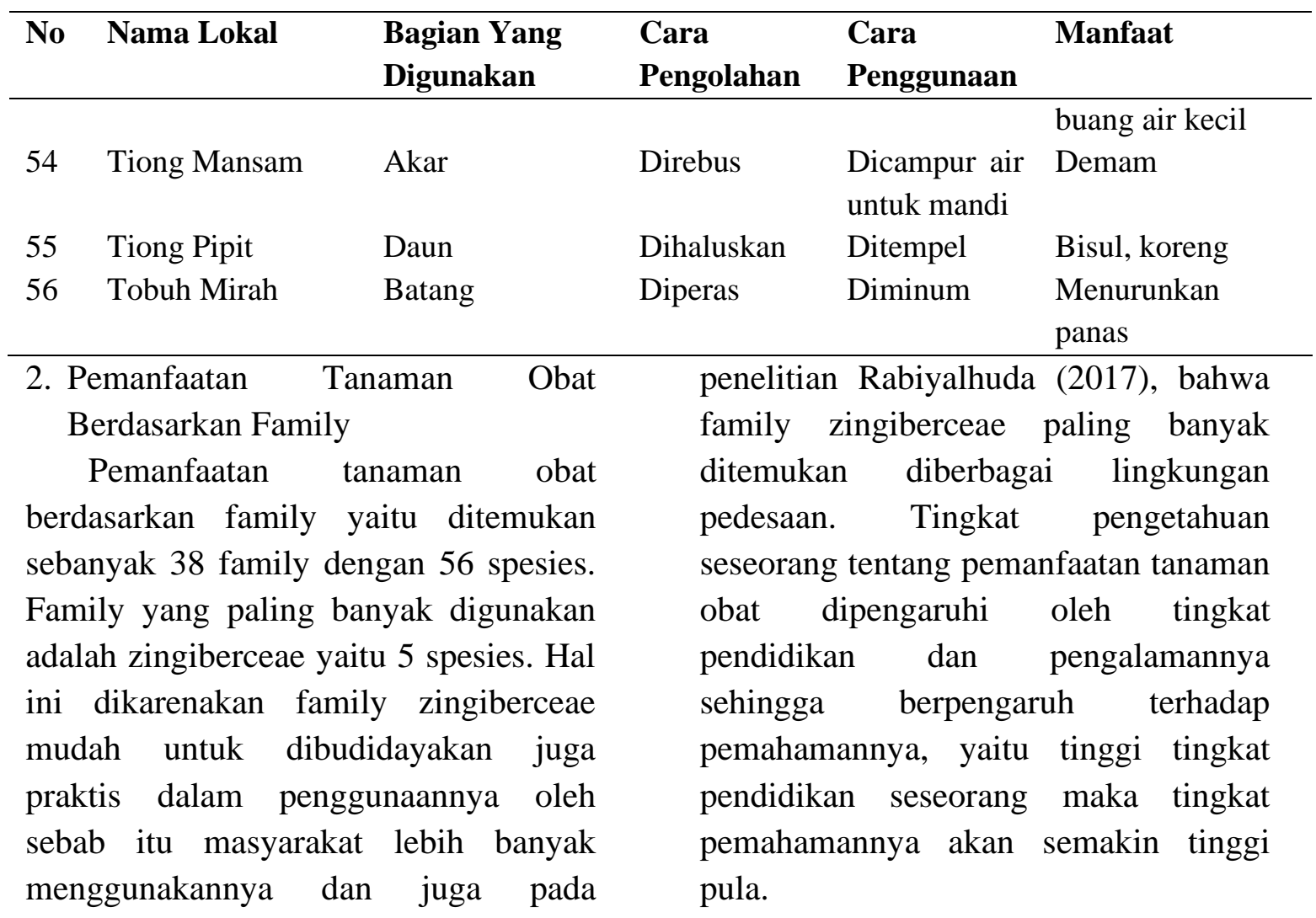

Tabel 3. Jumlah tanaman obat berdasarkan family (The number of medicinal plants based on family)

\begin{tabular}{llcc}
\hline No & Family & Jumlah spesies & Persentase (\%) \\
\hline 1 & Acanthaceae & 1 & 1,79 \\
2 & Amaranthaceae & 2 & 3,57 \\
3 & Annoaceae & 1 & 1,79 \\
4 & Araceae & 1 & 1,79 \\
5 & Arecaceae & 2 & 3,57 \\
6 & Asteraceae & 2 & 3,57 \\
7 & Athyriaceae & 1 & 1,79 \\
8 & Balsaminaceae & 1 & 1,79 \\
9 & Bombacaceae & 2 & 3,57 \\
10 & Caesalpiniaceae & 1 & 1,79 \\
11 & Campanulaceae & 1 & 1,79 \\
12 & Caricaceae & 1 & 1,79 \\
13 & Clusiaceae & 1 & 1,79 \\
14 & Combretaceae & 1 & 1,79 \\
15 & Commelinaceae & 1 & 1,79 \\
16 & Compositae & 1 & 1,79 \\
17 & Crassulaceae & 1 & 1,79 \\
18 & Euphorbiaceae & 1 & 1,79 \\
19 & Fabaceae & 2 & 3,57 \\
20 & Graminaceae & 1 & 1,79 \\
21 & Lamiaceae & 1 & 1,79 \\
22 & Liliaceae & 1 & 1,79 \\
23 & Malvaceae & 1 & 1,79
\end{tabular}




\begin{tabular}{llcc}
\hline No & Family & Jumlah spesies & Persentase (\%) \\
\hline 24 & Meliaceae & 1 & 1,79 \\
25 & Musaceae & 1 & 1,79 \\
26 & Myrthaceae & 1 & 1,79 \\
27 & Ocinaceae & 1 & 1,79 \\
28 & Oleaceae & 1 & 1,79 \\
29 & Oxalidaceae & 2 & 3,57 \\
30 & Palmae & 1 & 1,79 \\
31 & Piperaceae & 2 & 3,57 \\
32 & Poaceae & 4 & 7,14 \\
33 & Polypodiaceae & 2 & 3,57 \\
34 & Rubiaceae & 2 & 3,57 \\
35 & Solanaceae & 3 & 5,36 \\
36 & Thymelaceae & 1 & 1,79 \\
37 & Verbenaceae & 1 & 1,79 \\
38 & Zingiberaceae & 5 & 8,92 \\
\hline & Jumlah & 56 & 100 \\
\hline
\end{tabular}

3. Spesies Tanaman Obat Berdasarkan Habitus

Habitus tanaman obat yang banyak digunakan masyarakat berasal dari tingkat pohon yaitu 20 spesies dibandingkan tingkat liana hanya 2 spesies. Sesuai dengan penelitian Astria dkk (2013) di Dusun Semacol Kecamatan Balai Kabupaten Sanggau bahwa ternyata tingkat pohon, herba, dan perdu yang banyak digunakan yaitu 11 spesies $(33,33 \%)$. Ini dikarenakan untuk mendapatkannya sangat mudah karena ketersediaannya masih banyak dengan pergi ke hutan masyarakat sudah bisa mendapatkannya.

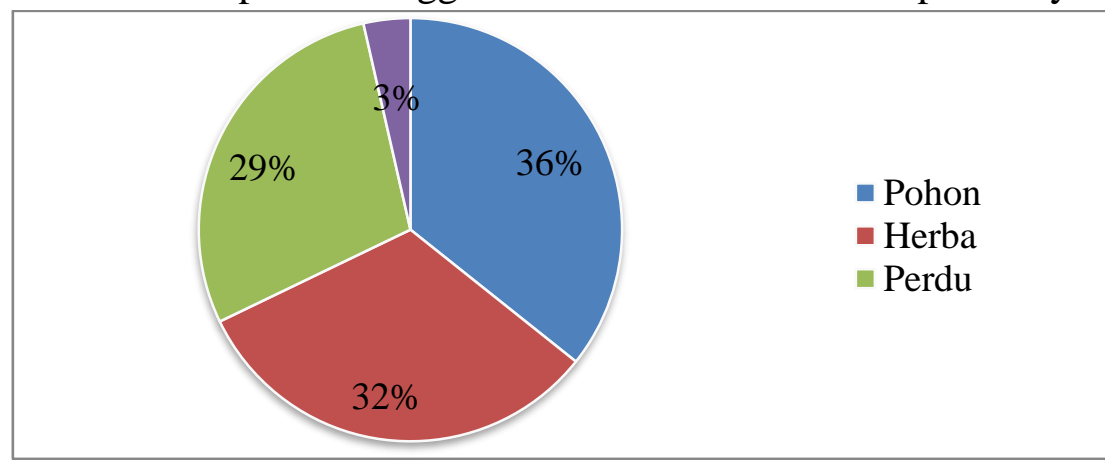

\section{Gambar 1. Jumlah spesies tanaman obat berdasarkan habitus (The number of medicinal plant species is based on habitus)}

4. Spesies Tanaman Obat Berdasarkan Bagian Yang Digunakan

Dalam pemanfaatan tanaman sebagai obat dan bagian-bagian tanaman yang biasa digunakan masyarakat untuk obat adalah bagian akar, batang, buah, daun dan rimpang. Setiap bagian tanaman memiliki khasiat yang berbeda. Bagian tanaman yang digunakan paling banyak untuk bahan baku obat adalah pada bagian daun yaitu 24 spesies. Seperti pada penelitian Efremila dkk (2015) yang dilakukan di Desa Kayu Tanam Mandor Kabupaten Landak menunjukkan bahwa bagian yang paling banyak digunakan adalah daun yaitu sebanyak 15 spesies (30\%). 
Diperkirakan dalam pengolahan masyarakat tidak memerlukan waktu lama, karena bagian daun bisa langsung dimakan dan di olah.

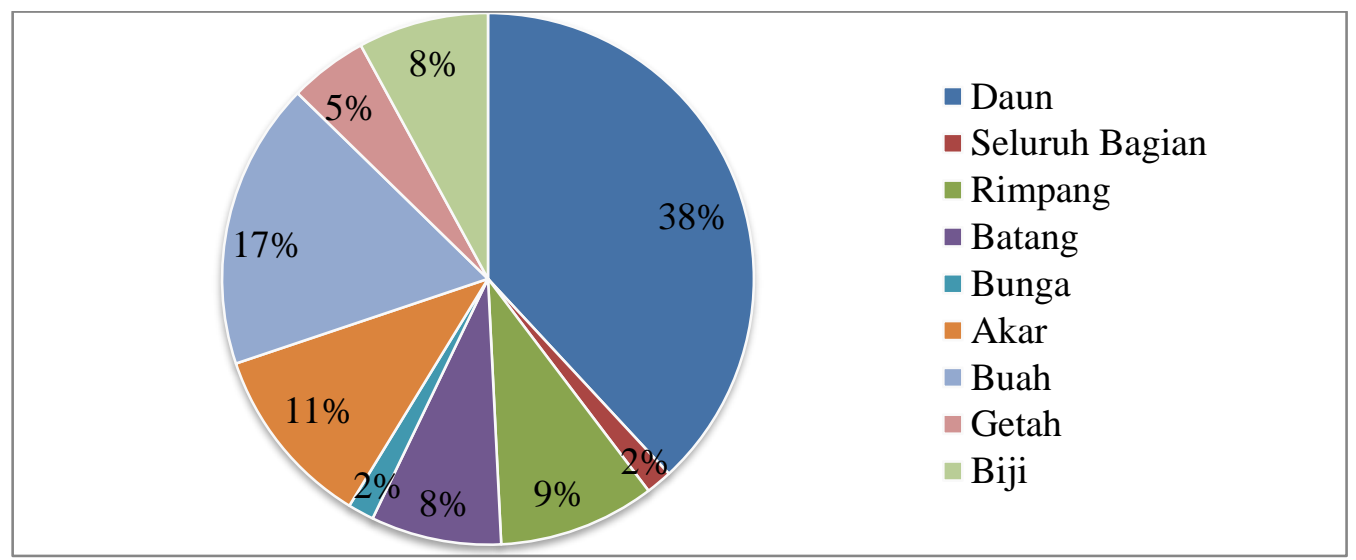

Gambar 2. Jumlah spesies tumbuhan obat berdasarkan bagian yang digunakan (The number of medicinal plant species based on the part used)

5. Pemanfaatan Tanaman Obat Berdasarkan Cara Pengolahan

Berdasarkan cara pengolahan tanaman obat, sebagian masyarakat masih menggunakan cara tradisonal, yaitu pengolahan dengan cara direbus, ditumbuk, dipanaskan maupun langsung dimakan. Cara pengolahan tanaman obat yang paling banyak digunakan oleh masyarakat tersebut dengan cara direbus yaitu 33 spesies, ditumbuk 14 spesies, langsung 7 spesies, dipanaskan 2

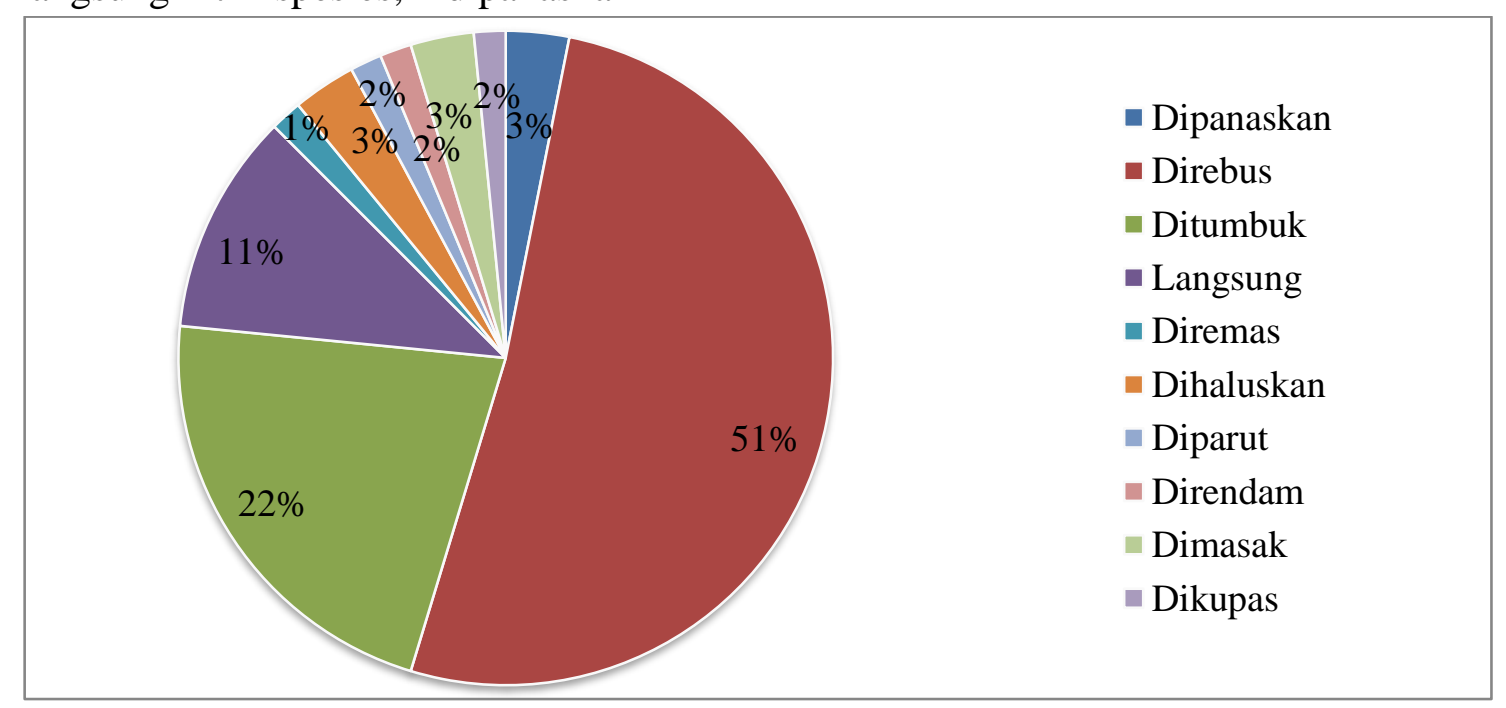

Gambar 3. Jumlah spesies tanaman obat berdasarkan cara pengolahan (The number of medicinal plant species is based on the method of processing) spesies, dihaluskan 2 spesies, dimasak 2 spesies, diremas 1 spesies, diparut 1 spesies, direndam 1 spesies, diperas 1 spesies, dan dikupas 1 spesies. Sesuai dengan penelitian Syah dkk (2014) yang dilakukan di Dusun Nekbare Desa Babane Kabupaten Bengkayang dimana dengan cara direbus paling banyak digunakan yaitu sebanyak 24 spesies. 
6. Spesies Tanaman Obat berdasarkan Cara penggunaan

Pengobatan dengan tanaman obat yang digunakan adalah untuk penyakit luar dan penyakit dalam. Cara penggunaan yang paling banyak digunakan yaitu dengan cara diminum yaitu 32 spesies, ditempel 15 spesies, dimakan 10 spesies, dioles 4 spesies dan dimandikan 1 spesies. Dilihat dari cara penggunaannya lebih banyak tumbuhan obat untuk mengobati penyakit dalam dibandingkan untuk mengobati penyakit luar.

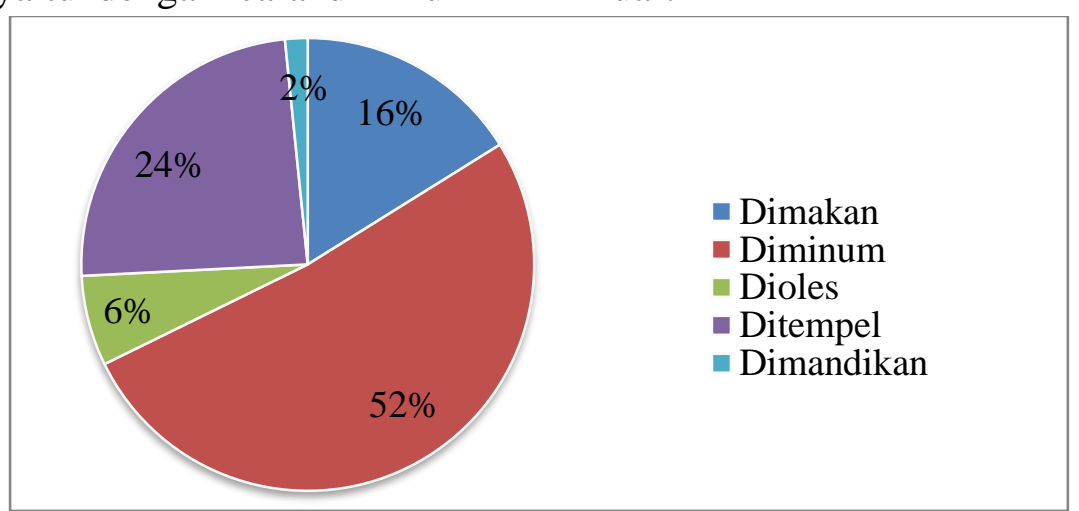

Gambar 4. Spesies tanaman obat berdasarkan cara penggunaannya (Medicinal plant species based on how they are used)

7. Spesies Tanaman Obat Berdasarkan Bentuk Ramuan

Berdasarkan jenis ramuan yang digunakan, masyarakat lebih banyak

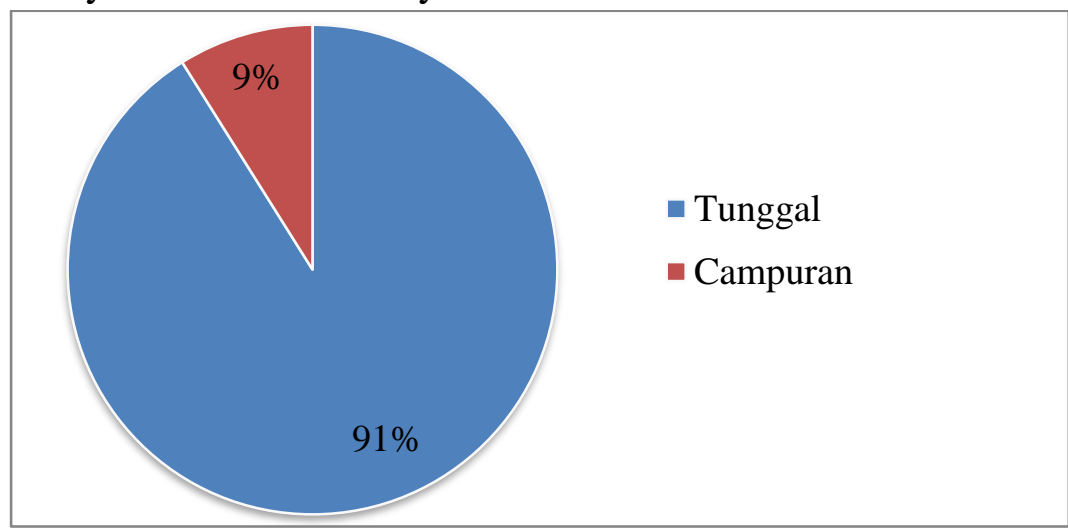

Gambar 5. Spesies tumbuhan obat berdasarkan bentuk ramuan (Medicinal plant species based on the form of the herb)

\section{KESIMPULAN}

Berdasarkan hasil penelitian terhadap jenis tanaman obat yang dimanfaatkan masyarakat di sekitar desa Semandang Kiri Kecamatan Simpang menggunakan jenis ramuan tunggal, yaitu ramuan yang tidak ada bahan lain sebagai campurannya. 
spesies dengan presentasi sebagai berikut :

a. Berdasarkan kelompok habitus ternyata tingkat pohon yang paling banyak dimanfaatkan sebagai obat yaitu sebanyak 20 spesies

b. Berdasarkan bagian tanaman yang digunakan ternyata bagian daun yang banyak dimanfaatkan sebanyak 24 spesies

c. Berdasarkan cara pengolahan ternyata cara direbus lebih banyak digunakan yaitu sebanyak 33 spesies

d. Berdasarkan penggunaannya, ternyata penggunaan dengan cara diminum yaitu sebanyak 32 spesies, ditempel sebanyak 15 spesies, dimakan sebanyak 10 spesies, dioles sebanyak 4 spesies dan di mandikan sebanyak 1 spesies.

e. Sedangkan berdasarkan bentuk ramuan, maka ramuan tunggal sebanyak 51 spesies, lebih banyak dari campuran sebanyak 5 spesies.

2. Satu jenis tumbuhan ternyata bisa untuk mengobati lebih dari 1 jenis penyakit.

\section{SARAN}

1. Untuk tetap terpelihara pengetahuan tentang jenis-jenis tumbuhan obat serta pemanfaatannya, maka perlu didiskripsikan dan didokumentasikan tentang pemanfaatan tanaman obat.

2. Perlunya dilakukan penelitian lanjutan mengenai tumbuhan obat di Desa Semandang Kiri Kecamatan
Simpang Hulu karena masih banyak tumbuhan obat yang belum diketahui pemanfaatannya.

3. Perlu dibuat percontohan tanaman pekarangan di halaman kantor Desa Semandang Kiri, agar masyarakat termotivasi untuk memanfaatkan pekarangannya dengan tanaman obat.

\section{DAFTAR PUSTAKA}

Armiwoltywa, C. 2011. Pemanfaatan Tumbuhan Obat Terhadap Tingkat Pengetahuan Masyarakat di Lokasi Hutan Adat Bukit Padarang Dusun Marinso Kabupaten Landak. Skripsi Mahasiswa Fakultas Kehutanan Universitas Tanjungpura Pontianak. (Tidak Di Publikasikan)

Astria, Budhi S, Sisilia L. 2013. Kajian Etnobotani Tumbuhan Obat Pada Masyarakat Dusun Semoncol Kecamatan Balai Kabupaten Sanggau. Jurnal Hutan Lestari. Vol 1 (3).

Efremila, Wardenaar E, Sisilia L. 2015. Studi Etnobotani Tumbuhan Obat Oleh Etnis Suku Dayak Di Desa Kayu Tanam Kecamatan Mandor Kabupaten Landak. Jurnal Hutan Lestari. Vol 3 (2):234-246

Leonardo, Usman F.H, Yusro F. 2013 Kajian Etnobotani Tumbuhan Obat di Desa Sekabuk Kecamatan Sadaniang Kabupaten Pontianak. Jurnal Hutan Lestari Vol 1 (1).

Maryadi. 2012. Studi Etnobotani Tumbuhan Obat di Desa Seriang Kecamatan Bedau Kabupaten Kapuas Hulu. Skripsi 
Mahasiswa Fakultas Kehutanan Universitas Tanjungpura

Pontianak.

Nurhaida, Usman F.H, Tavita G.E. 2015 Studi Etnobotani tumbuhan Obat di Dusun Kelampuk Kecamatan Tanah Pinoh Barat Kabupaten Melawi. Jurnal Hutan Lestari. Vol 3 (4):526537.

Rabiyalhuda, 2017. Pemanfaatan Tumbuhan Obat Oleh
Masyarakat Desa Loka Jaya Di Kecamatan Tanah Pinoh Kabupaten Melawi. Skripsi Fakultas Kehutanan. Universitas Tanjungpura. Pontianak.

Syah J, Usman F.H, Yusro F. 2014 Studi Tumbuhan Obat Yang Dimanfaatkan Masyarakat Dusun Nekbare Babane Kecamatan Samalantan Kabupaten Bengkayang. Jurnal Hutan Lestari. Vol 2 (3). 